\title{
The Ribosome: Some Hard Facts about Its Structure and Hot Air about Its Evolution*
}

\author{
V. RAMAKRISHNAN \\ MRC Laboratory of Molecular Biology, Cambridge CB2 0QH, United Kingdom \\ Correspondence:ramak@mrc-lmb.cam.ac.uk
}

\begin{abstract}
By translating genetically encoded information to synthesize proteins, the ribosome has a central and fundamental role in the molecular biology of the cell. Virtually every molecule made in every cell was made either directly by the ribosome or by enzymes made by the ribosome. Although the ribosome was discovered half a century ago, progress in the field of translation has been revolutionized by the atomic structures of the ribosomal subunits determined in 2000. These structures paved the way not only for more sophisticated biochemical and genetic experiments, but also for the phasing and/or molecular interpretation of all subsequent structures of the ribosome by crystallography or cryoEM (cryo-electron microscopy). In addition to facilitating our understanding of ribosome function, these structures also shed light on the evolution of the ribosome.
\end{abstract}

Ribosomes from all species consist of approximately two-thirds RNA and one-third protein. Ribosomes from mammalian mitochondria are an exception, with the ratio of protein and RNA reversed (see Sharma et al. 2003). All ribosomes consist of two subunits, termed 50S and 30S in bacteria or $60 \mathrm{~S}$ and $40 \mathrm{~S}$ in eukaryotes. Together, they comprise the $70 \mathrm{~S}$ ribosome in bacteria or the $80 \mathrm{~S}$ ribosome in eukaryotes (Fig. 1A). The mRNA containing the genetic template binds in a cleft in the small subunit. The amino acids themselves are brought into the ribosome by aminoacylated tRNA substrates. The ribosome has three binding sites for tRNA: the A (aminoacyl) site that brings the new aminoacyl tRNA, the P (peptidyl) site that holds the nascent peptide chain, and the E (exit) site to which the deacylated P-site tRNA moves after peptide bond formation (Fig. 1B).

Translation in all species can be divided into three stages (Fig. 2) (for review, see Schmeing and Ramakrishnan 2009). During initiation, the small subunit of the ribosome binds mRNA at the start site of the coding sequence, in a precise manner that puts the start codon in the $\mathrm{P}$ site. This requires three initiation factors and a special initiator tRNA that binds to the $\mathrm{P}$ site.

Initiation is followed by the elongation cycle, which consists of three important steps: decoding, peptidyl transfer, and translocation. During decoding, the correct aminoacyl tRNA, which is delivered to the A site of the ribosome as a ternary complex with elongation factor $\mathrm{Tu}$ (EF-Tu) and GTP, is selected based on the codon on the mRNA in the A site. Selection of the tRNA leads to hydrolysis of GTP by EF-Tu and release of the factor from the ribosome. The aminoacyl end of the selected tRNA then swings into the peptidyl transferase center (PTC) in the 50S subunit of the ribosome, where peptide bond formation occurs rapidly and spontaneously.

*The title is a paraphrase of one by the late eminent crystallographer David M. Blow: "Hard facts on structure: Hot air about mobility" (Nature [1982] 297: 454-455).
Peptidyl transfer leaves the P-site tRNA deacylated, with the A-site tRNA now containing a nascent peptide chain that has been extended by one residue. The $3^{\prime}$ ends of the A- and P-site tRNAs then move first with respect to the 50S subunit to form an intermediate or hybrid state of the ribosome, followed by movement of the mRNA and tRNAs with respect to the $30 \mathrm{~S}$ subunit, which requires the action of EF-G, another GTPase factor. This leaves the ribosome with an empty A site with a new mRNA codon ready to accept the next aminoacyl tRNA.

The elongation cycle continues until a stop codon is reached in the A site. The so-called class I release factors (RF1 or RF2 in bacteria, eRF1 in eukaryotes) recognize the stop codon and catalyze the cleavage of the polypeptide chain from the P-site tRNA. Finally, a factor known as ribosome recycling factor (RRF), with the help of EF$\mathrm{G}$, disassembles the ribosome so that a new round of protein synthesis can begin.

Most of these aspects of translation are common to all kingdoms of life. In eukaryotes, initiation is far more complex and involves a specifically modified mRNA with a $5^{\prime}$ cap and a poly(A) tail at the $3^{\prime}$ end, as well as almost a dozen factors, many of which are large multisubunit complexes themselves (Kapp and Lorsch 2004).

Recent structural and biochemical work has shed light on many aspects of translation. In particular, the high-resolution structures of the ribosomal subunits (Ban et al. 2000; Wimberly et al. 2000) were useful in the molecular interpretation and/or phasing of all subsequent structures, including a lower-resolution crystal structure of the $70 \mathrm{~S}$ ribosome with mRNA and tRNA ligands at 5.5- $\AA$ resolution (Yusupov et al. 2001), more recent higher-resolution structures of the empty $70 \mathrm{~S}$ ribosome from Escherichia coli (Schuwirth et al. 2005), and the 70S ribosome with mRNA and tRNAs from Thermus thermophilus (Selmer et al. 2006). These basic structures have been followed by high-resolution structures of the ribosome with protein factors, most notably with release factors (Laurberg et al. 


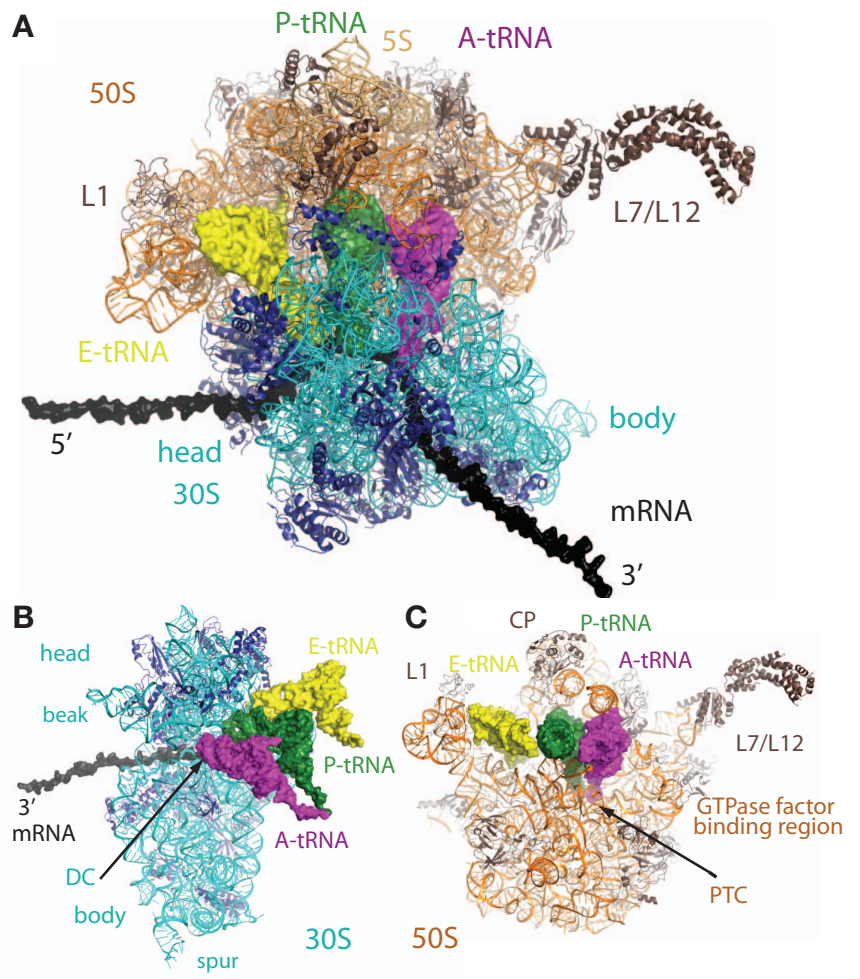

Figure 1. Structure of the ribosome. (A) Overview of the bacterial $70 \mathrm{~S}$ ribosome with the $50 \mathrm{~S}$ subunit on top and the $30 \mathrm{~S}$ subunit on the bottom. The mRNA (dark gray) is shown wrapped round the neck of the $30 \mathrm{~S}$ subunit. (Magenta) A-site, (green) P-site, (yellow) E-site tRNAs. $(B)$ The $30 \mathrm{~S}$ subunit showing the decoding center (DC) where codon-anticodon interactions are monitored during tRNA selection. $(C)$ The $50 \mathrm{~S}$ subunit showing the GTPase-factor-binding region and the PTC where peptide bond formation is catalyzed. (Reprinted, with permission, from Schmeing and Ramakrishnan 2009 [@Nature Publishing Group].)

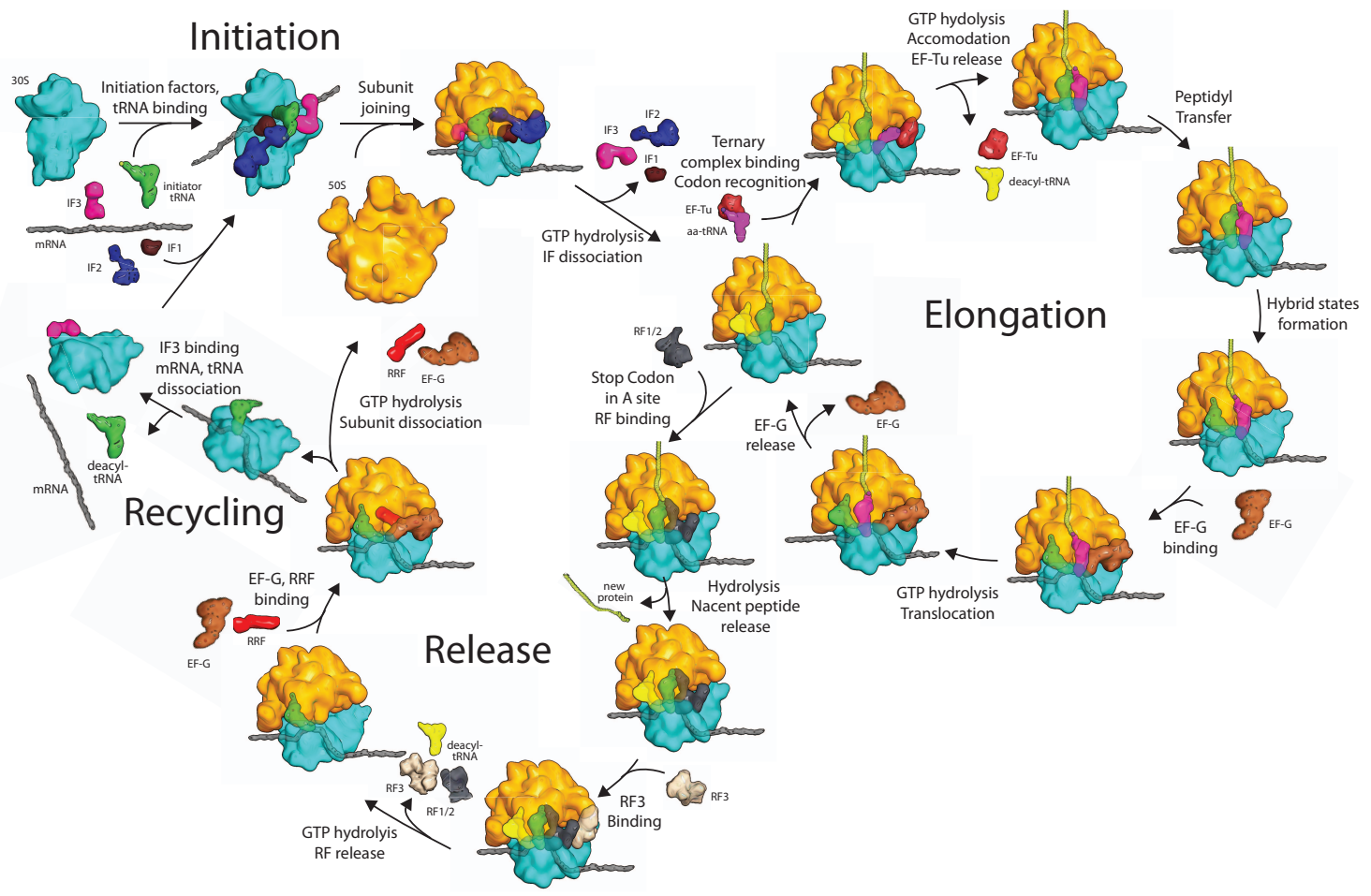

Figure 2. Overview of the translational pathway showing the phases of initiation, elongation, release, and recycling. (Reprinted, with permission, from Schmeing and Ramakrishnan 2009 [CNature Publishing Group].) 
2008; Weixlbaumer et al. 2008) and more recently with elongation factors EF-Tu and EF-G (Gao et al. 2009; Schmeing et al. 2009). In addition, many cryoEM structures of the ribosome represent different functional states at varying resolutions.

\section{THE RIBOSOME AS AN RNA-BASED MACHINE}

The ribosome itself is a large and complex assembly of RNA and more than 50 proteins. In addition, translation requires a host of protein factors and aminoacyl tRNA substrates. Thus, understanding the evolution of the ribosome poses a difficult challenge. To begin with, the system poses the standard "chicken or egg" question: If the ribosome consists of both RNA and protein, and is needed to make protein, how did it come about? The first attempt to address this was Crick, who presciently wrote, "It is tempting to wonder if the primitive ribosome could have been made entirely of RNA" (original italics) (Crick 1968). To my knowledge, this was the first idea that RNA could be both an information carrier and able to perform catalysis, and can be thought of as the origin of the "RNA world hypothesis," which postulates a primordial world consisting of replicating RNA molecules before the advent of proteins. However, in the absence of any known examples of catalysis by RNA, not even Crick could imagine that catalysis in the current ribosome would be RNA based.

It is clear that protein factors could have evolved later to make translation more efficient, because even today it is possible to get inefficient and limited translation without them. For instance, factor-free protein synthesis in vitro was demonstrated by Spirin and coworkers (Gavrilova and Spirin 1974; Gavrilova et al. 1976). But what about the ribosome itself? What are the relative roles of protein and RNA?

The earliest work on ribosome function focused on proteins for two reasons. Partly, proteins were thought to be the molecules responsible for catalytic function. Second, because the standard laboratory organism $E$. coli contains seven genes for rRNA, it was difficult to isolate RNA mutants, and many of the early mutations, such as those for antibiotic resistance, mapped to ribosomal proteins. However, there were hints from quite early on that RNA had a more important role than just providing a scaffolding for functional proteins. For instance, it was shown that chemical modification of rRNA but not proteins would abolish binding of tRNA to 30S subunits (Noller and Chaires 1972). In the absence of any prior evidence for the catalytic properties of RNA, the results were taken to suggest that tRNA-binding sites must therefore consist of both protein and RNA. Subsequent work on the ribosome, notably by Noller and coworkers, continued to provide evidence for the importance of rRNA, but in the absence of an intellectual framework in which RNA catalysis was a real possibility, it was hard to make definite progress.

This situation changed dramatically when catalysis by RNA was discovered in the context of the group I intron (Zaug et al. 1983) or RNase P (Guerrier-Takada et al. 1983). With evidence that RNA could in principle perform catalysis, the ribosome community was far readier to accept that rRNA might have crucial functions, and this prospect renewed interest in the field (Moore 1988). Subsequently, an experiment showed that $50 \mathrm{~S}$ subunits from Thermus aquaticus treated extensively with proteinase $\mathrm{K}$ in the presence of SDS nevertheless preserved their peptidyl transferase activity (Noller et al. 1992). This experiment was a major step forward, but not conclusive proof for a variety of reasons. E. coli $50 \mathrm{~S}$ subunits did not maintain activity with such protease treatment, nor did in-vitrotranscribed 23S RNA show activity. Moreover, in the Thermus 50S subunit, a large number of protein fragments remained bound after protease treatment, and indeed, subsequent work showed that the treatment left three proteins essentially intact (Khaitovich et al. 1999). A subsequent effort to provide conclusive proof of the role of RNA in peptidyl transfer using in vitro transcription of 23S RNA and its individual domains appeared to have narrowed down the activity to the RNA domain containing the peptidyl transferase center (Nitta et al. 1998), but this work was retracted a year later (Nitta et al. 1999). Thus, although work on the group I intron and RNase P showed that catalysis by RNA was certainly possible, conclusive evidence for a similar role in the ribosome proved to be difficult to obtain by purely biochemical means. It is striking that this limitation was recognized very early on by Crick, who said, "Without a detailed knowledge of the structure of present-day ribosomes it is difficult to make an informed guess" (Crick 1968).

High-resolution structures of ribosomal subunits and the whole ribosome have revealed in stunning detail the environment of the PTC-, tRNA-, and mRNA-binding sites, the intersubunit interface, and many other functionally important regions of the ribosome. These structures at long last allow us to provide conclusive insights into many aspects of ribosome function and, in particular, show unambiguously how widespread the role of RNA is in the contemporary ribosome.

\section{DECODING BY tRNA}

A crucial event in protein synthesis is the selection of the correct tRNA corresponding to the codon on mRNA. At a fundamental level, this involves base pairing between the codon and the anticodon on tRNA. However, the free energy of base pairing between codon and anticodon is not sufficient to explain the relatively low error rate of the ribosome (Ogle and Ramakrishnan 2005). Kinetic experiments show that binding of the correct tRNA leads to induced conformational changes in the ribosome that accelerate GTP hydrolysis by EF-Tu and tRNA selection (see Rodnina and Wintermeyer 2001).

\section{Minor Groove Recognition by RNA}

Discrimination against incorrect tRNA ultimately depends on recognizing mismatched base pairs. Because base pairing alone is insufficient to explain the accuracy of decoding, and the ribosome appears to have an active role, what is the ultimate nature of this discrimination? Experiments showed that the binding of a cognate tRNA 
induced three universally conserved bases in the decoding center of the $30 \mathrm{~S}$ subunit to line the minor groove between codon and anticodon in a manner that would distinguish between canonical Watson-Crick and noncanonical base pairs at the first two positions but did not monitor the geometry of base pairing at the wobble position (Fig. 3) (Ogle et al. 2001). This finding at once explained the additional discrimination provided by the ribosome and the long-standing nature of the genetic code, in which mismatches were allowed at the wobble

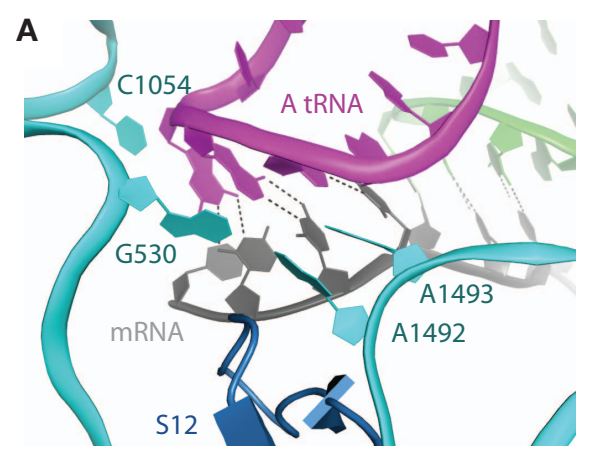

B

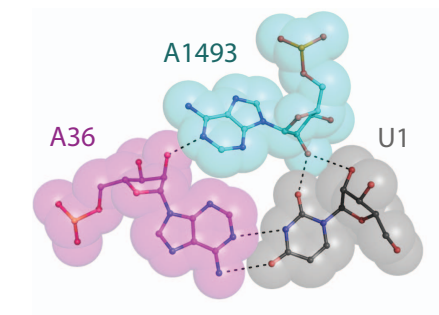

C

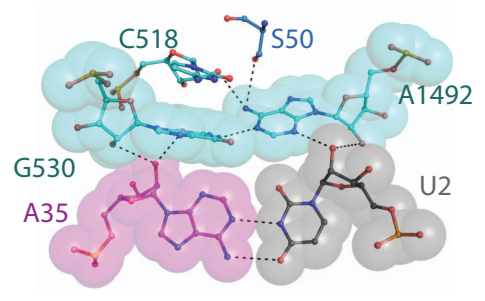

D

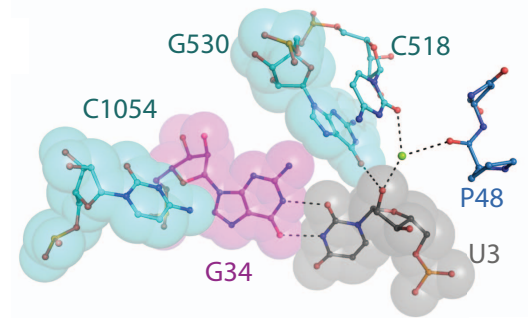

Figure 3. $(A)$ Decoding center in the $30 \mathrm{~S}$ subunit of the ribosome, showing how ribosomal bases interact with the minor groove of the codon-anticodon minihelix. $(B-D)$ Interaction of ribosomal bases with the minor groove of the first, second, and third base pairs between the codon (pink) and anticodon (gray) (Ogle et al. 2001). (Reprinted, with permission, from Schmeing and Ramakrishnan 2009 [@Nature Publishing Group].) position but not at the first two positions (Crick 1966). The additional binding energy of cognate tRNA from the induced changes at the decoding center resulted in largescale movements of the shoulder domain of the 30S subunit, whereas near-cognate tRNA failed to produce such movements (Ogle et al. 2002). This finding led to a model in which the conformational change from an open form to a closed form was required for tRNA selection; such a model could help to rationalize disparate biochemical genetic data on fidelity (Ogle et al. 2002). The rationale for why such a conformational change is needed for tRNA selection has recently been further clarified by the structure of the ribosome bound to elongation factor $\mathrm{Tu}$ and tRNA (Schmeing et al. 2009).

\section{The Possible Role of Minor-groove Recognition in Evolution}

DNA and RNA polymerases have exactly the same problem of discriminating against noncanonical base pairs. They are even more accurate than the ribosome. It is striking that both DNA and RNA polymerases use conserved amino acids to monitor the minor groove between the template and transcript strands. Indeed, it is possible for the polymerases to choose base pairs that form no hydrogen bonds between them, as long as they have the same shape as Watson-Crick base pairs at the minor groove (for review, see Kool 2000). Thus, minor-groove recognition is an important feature of ensuring proper base pairing complementarity.

The ribosome shows that such minor-groove recognition can be done by RNA alone. This is significant for the evolution of complexity from a primitive self-replicating RNA system. Such a system initially would have had a very high error rate, because base pairing alone would not have a sufficiently high free-energy difference to allow for substantial accuracy. However, if a primitive replicase also evolved to take advantage of minor-groove recognition of complementary base pairs, the error rate would be reduced by at least two orders of magnitude, allowing for the much more accurate replication required for complex systems to evolve.

\section{Distortions in tRNA during Decoding}

Structures of the ribosome complexed with EF-Tu and tRNA by cryoEM (Valle et al. 2002; Schuette et al. 2009; Villa et al. 2009) or more recently by crystallography (Schmeing et al. 2009) show that when tRNA is delivered to the ribosome by EF-Tu, it is distorted in the anticodon stem (Fig. 4). This suggests that the tRNA molecule has within itself considerable conformational variability. It is possible that this distortion could occur transiently in the absence of EF-Tu. Thus, tRNA in the absence of factors could have still performed decoding in a very similar way, with a transient bend during initial recognition followed by accommodation of the aminoacyl end into the PTC. However, GTP hydrolysis by EF-Tu, an important step in tRNA selection, would have been absent, so that the process would have been both slower and less accurate. 
A

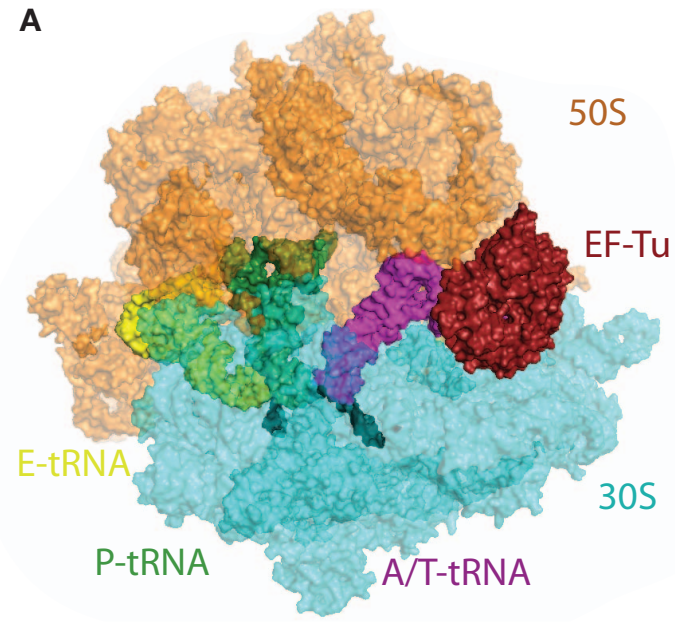

B

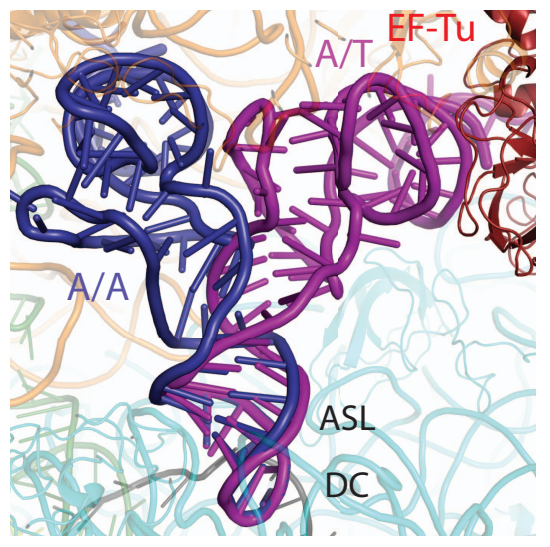

Figure 4. Structure of the complex of EF-Tu and aminoacyl tRNA bound to the ribosome. (A) Overview showing EF-Tu and aminoacyl tRNA (purple) bound to the ribosome. $(B)$ Comparison of the conformation of the tRNA in the distorted state when it is bound to EF-Tu (purple) with the more canonical form after it has swung into the peptidyl transferase center (dark blue). ( $A$, Reprinted, with permission from Schmeing and Ramakrishnan 2009 [CNature Publishing Group]; B, reprinted, with permission from Schmeing et al. 2009 [CAAAS].)

\section{PEPTIDYL TRANSFER}

The central chemical event in translation is the formation of the peptide bond between the nascent polypeptide chain on P-site tRNA and the incoming amino acid on Asite tRNA. This catalysis occurs in the PTC of the ribosome that is located in the $50 \mathrm{~S}$ subunit. As we have discussed above, the question of whether catalysis is RNA-based or whether proteins are involved could not be settled by purely biochemical experiments.

It was therefore striking that the structure of the $50 \mathrm{~S}$ subunit in complex with a transition-state analog that defined the catalytic site showed that there were no proteins within $18 \AA$ of the active site (Nissen et al. 2000). Although an acid-base catalytic mechanism involving specific ribosomal bases was proposed, this was disproved by subsequent biochemical work (for review, see Rodnina et al. 2006). Interestingly, none of the ribosomal bases appear to have a catalytic role in the chemical sense of contributing or accepting electrons or protons. Rather, the ribosome's contribution appears to be primarily entropic, by holding the substrates in the proper orientation (Sievers et al. 2004). The one moiety that appears to have a chemical role is the $2^{\prime}-\mathrm{OH}$ of the terminal adenosine of P-site tRNA itself, showing that the ribosome is an example of substrate-assisted catalysis (Weinger et al. 2004).

One interesting role for the ribosome is that of exposing the ester bond on the P-site tRNA to nucleophilic attack by an induced conformational change in the PTC on A-site tRNA binding (Schmeing et al. 2005b). This is an elegant way of protecting the nascent chain from hydrolysis by water except when the proper A-site substrate is bound, when certain conserved bases move to expose the ester bond that links the nascent chain to P-site tRNA. As in the case of decoding, the induced conformational changes all involve the RNA component of the ribosome.
Although no proteins were found near the active site of the archaeal PTC (Nissen et al. 2000), studies in bacteria have long implicated specific proteins in peptidyl transfer. In particular, two proteins, L16 (Moore et al. 1975) and L27 (Wower et al. 1998), were shown to aid peptidyl transfer. Of these, L27 was known to cross-link to the 3' ends of both A- and P-site tRNAs, thus placing it right at the PTC (Wower et al. 1998), and just deletion of the first few amino-terminal residues reduced both the cross-linking yield and the rate of peptidyl transfer (Maguire et al. 2005).

The role of these proteins has recently been clarified by crystallography, in which it was shown that L16 becomes ordered and helps to stabilize A-site tRNA, whereas L27 has a long extension that places its amino terminus right at the PTC where it interacts with both A- and P-site tRNAs (Fig. 5) (Voorhees et al. 2009). Thus, at least in the bacterial ribosome, the PTC does have a protein component that has some role in facilitating peptidyl transfer by stabilizing tRNA substrates. In so doing, its role is not fundamentally different from that of rRNA. However, one should bear in mind that it is possible to delete L27 without affecting viability, but the deletion of many conserved RNA residues near the PTC is lethal. So the notion that the ribosome is fundamentally an RNA-based machine is unchanged, but clearly in viewing the contemporary ribosome, we are seeing a snapshot in evolution in which proteins are beginning to play a supporting role.

\section{PEPTIDE RELEASE}

The process of termination has analogies with both decoding and peptidyl transfer because the stop codon must be recognized and catalysis of the release of the peptide chain must take place at the PTC.

A significant advance has been made recently, owing to the crystal structures of both RF1 and RF2 bound to the 
A

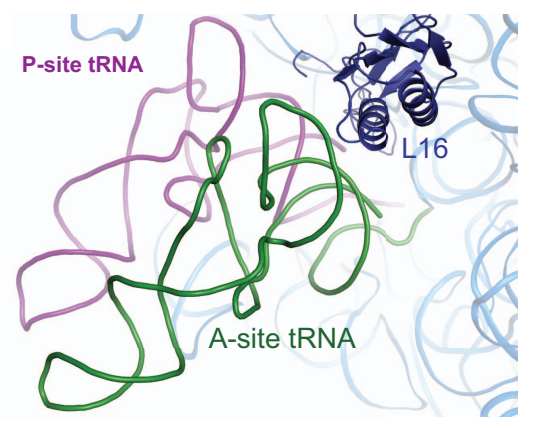

B
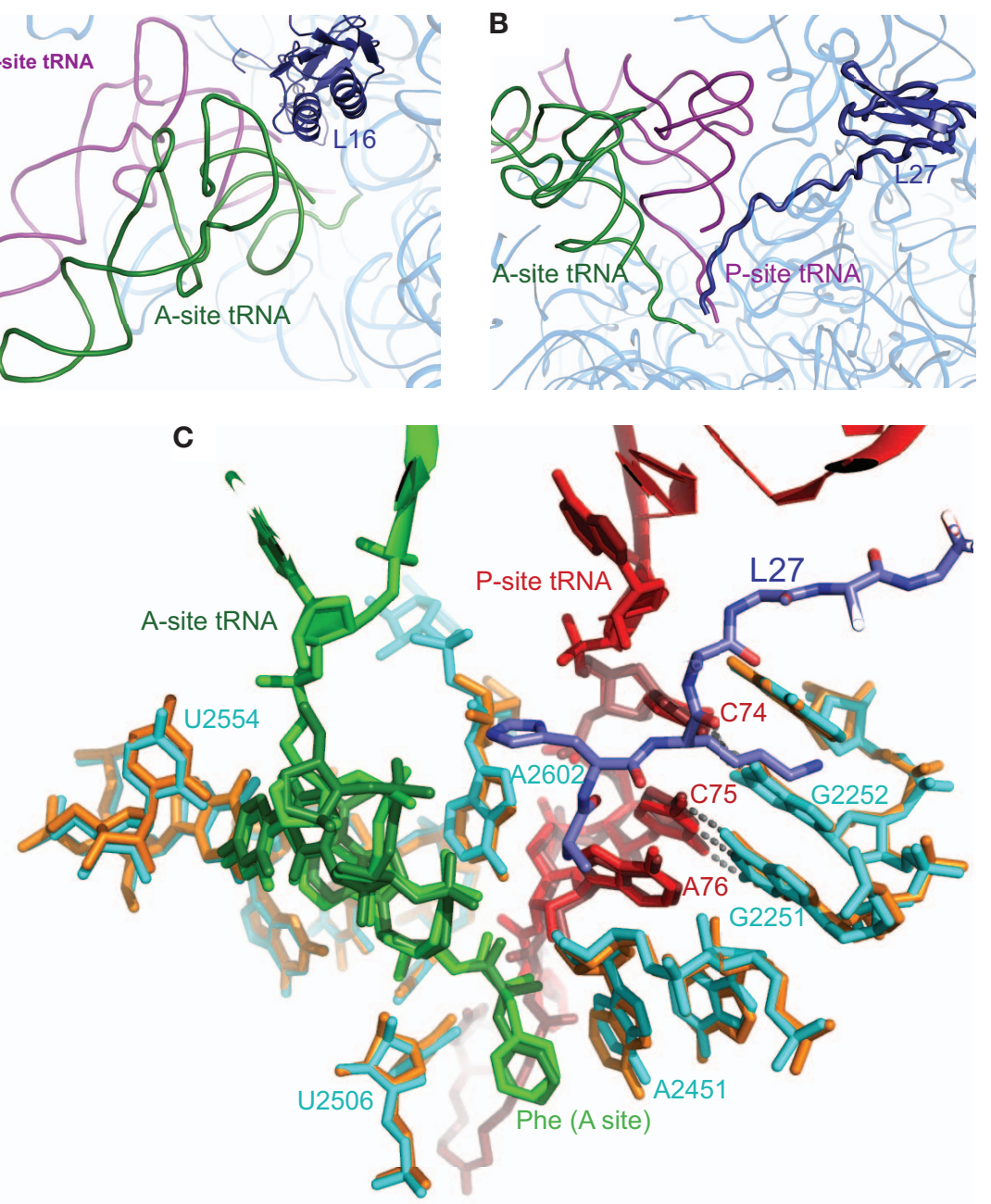

Figure 5. The peptidyl transferase center of the ribosome. $(A, B)$ Location of two proteins that aid peptidyl transfer activity by stabilizing tRNA substrates. $(C)$ Details of the bacterial PTC with A-site tRNA (green), P-site tRNA (red), and 23S RNA (cyan). A superposition with the archaeal peptidyl transferase center (1VQN, from Schmeing et al. 2005a) with the tRNAs in a slightly darker shade and the 23S RNA (orange) shows that bacterial and archaeal PTC are virtually identical. However, in bacteria, the amino-terminal tail of protein L27 is right at the PTC. ( $A$ and $B$, Reprinted, with permission, from Voorhees et al. 2009 [CNature Publishing Group].)

ribosome (Korostelev et al. 2008; Laurberg et al. 2008; Weixlbaumer et al. 2008). These structures shed light on both the mechanism of codon recognition by these factors and the role of a conserved GGQ motif in catalysis. In particular, an induced fit of the same three nucleotides involved in decoding by tRNA is required for proper recognition of the stop codon by release factors. Moreover, a similar induced fit on the binding of the GGQ motif in the PTC is seen on release factor binding as was seen for tRNA binding, except in this case, instead of a nucleophilic attack by the amine on A-site tRNA, there is presumably an attack by a water molecule that leads to hydrolysis of the nascent chain.

It is striking that bacterial and eukaryotic release factors have no sequence or structural homology. This suggests that despite their common GGQ motif at the catalytic site, they evolved independently after the divergence of the three kingdoms. If this is true, it is likely that the role of termination was originally played by a tRNA.
Presumably, such a tRNA had anticodons complementary to a stop codon so that decoding could occur, but no synthetase was associated with them, so that they bound in the deacylated form by the more inefficient factor-free route, rather than as a complex associated with EF-Tu. They could then still induce a change in the PTC that would expose the ester bond to nucleophilic attack by water. This hypothesis is supported by the fact that even in the contemporary ribosome, deacylated tRNA promotes peptide release but not as efficiently as release factors (Zavialov et al. 2002). Presumably, release factors, in particular their properly positioned GGQ motif, more optimally coordinate a water for hydrolysis of the nascent peptide chain. They may also be more efficient at stop codon discrimination, because they have a very low error rate without the proofreading present in normal decoding (Freistroffer et al. 2000). Nevertheless, the structural and biochemical data clearly suggest how a protein factor has taken over a role once likely performed by tRNA. 


\section{TRANSLOCATION}

The sequential nature of protein synthesis requires that the ribosome be able to move relative to mRNA and tRNA after each round of addition of an amino acid to the growing protein chain. This process, translocation, is highly complex and involves large-scale movements that must result in the precise movement by one codon to preserve the reading frame.

The idea that all ribosomes have two subunits because they need to move relative to one another was proposed a long time ago (Bretscher 1968; Spirin 1968). One of these proposed that the tRNAs move first relative to one subunit and only then with respect to the other to generate hybrid states (Bretscher 1968), an idea that was borne out almost two decades later in a landmark experiment using chemical footprinting of rRNA (Moazed and Noller 1989). More recent cryoEM experiments have shown that the ribosomal subunits "ratchet" or rotate relative to one another during translocation (Frank and Agrawal 2000; Valle et al. 2003), and the formation of hybrid states is indeed directly related to this ratcheting movement (Ermolenko et al. 2007).

Strikingly, the interface between the two subunits consists mainly of RNA. This suggests that the features required to ratchet as part of translocation may have existed even in a primordial protein-free ribosome. The finding that factor-free translation, however inefficient, can occur under certain conditions is in keeping with this idea (Gavrilova and Spirin 1974).

\section{Energy Stored in tRNA}

If GTP hydrolysis by EF-G is not strictly required for translocation, what determines the directionality of the movement? The progression of tRNA from A to P to $\mathrm{E}$ sites involves a progression of changes in its chemical state, from aminoacyl to peptidyl to deacylated. As has been pointed out previously (Spirin 1985; Noller 2005), the affinity of the various sites has evolved so that changes in the chemical state of tRNA would allow it to progress to the next site on thermodynamic grounds alone. Moreover, Noller has pointed out that the energy from peptide bond formation could be used to drive the process even in the absence of GTP hydrolysis by translational factors (Noller 2005).

Interestingly, it has been observed that the P-site tRNA is distorted relative to free tRNA in solution (Selmer et al. 2006). If tRNA is allowed to relax, e.g., after peptide bond formation when it becomes deacylated, the direction of relaxation would be such as to move it toward the E site. Therefore, some of the energy required may be stored in the distortion in P-site tRNA itself.

\section{E Site: Conservation and Role}

A particular role of the $\mathrm{E}$ site in this process could be to trap the intermediate state of translocation by binding the $3^{\prime}$ end of the tRNA that has moved from the P site of the $50 \mathrm{~S}$ subunit, resulting in a hybrid P/E tRNA. By stably trapping this intermediate, the E site would facilitate translocation.

A comparison of the structures of the $3^{\prime}$ end of tRNA in a bacterial 50S subunit (Korostelev et al. 2006; Selmer et al. 2006) with that in an archaeal 50S subunit (Schmeing et al. 2003) reveals some interesting similarities and differences. The E site can only bind a deacylated tRNA, and the terminal adenine with its $2^{\prime}-\mathrm{OH}$ is required (Lill et al. 1989; Feinberg and Joseph 2001). This requirement is consistent with its role in trapping deacylated tRNA. Interestingly, both bacterial and archaeal E sites bind the terminal adenine in exactly the same way (Fig. 6). In both cases, the adenine base is intercalated between two conserved purines of 23S RNA and makes identical contacts with a conserved cytidine. This strongly suggests that the E site evolved even before the split among the three kingdoms. Outside the vicinity of the terminal adenine, E-site interactions are quite different. This divergence suggests that those interactions are less essential.

\section{HOW DID THE RIBOSOME EVOLVE?}

Recent structures of the ribosome have shown unambiguously that the essential functions of the ribosome such as decoding, peptidyl transfer, and translocation all appear to be mediated by RNA. The evolution of the ribosome has been much discussed (see, e.g., reviews by Moore 1993; Noller 2005), but there is little detailed understanding of how the process might have occurred. One interesting observation from the structure of the $50 \mathrm{~S}$ subunit is that the PTC itself has a twofold symmetry that extends beyond the binding sites for A- and P-site tRNAs (Bashan et al. 2003). This suggests that an independently folded domain of RNA may have been duplicated to cre-

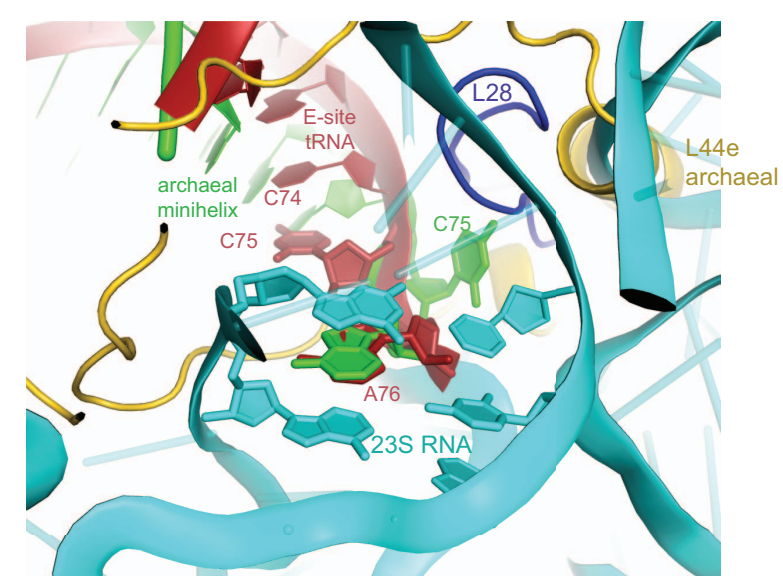

Figure 6. tRNA E site in the 50S subunit of the ribosome. A comparison of the bacterial E-site tRNA (reddish brown) (Selmer et al. 2006) with a minihelix representing the $3^{\prime}$ acceptor arm of tRNA in the archaeal ribosome (green) (Schmeing et al. 2003) shows that the terminal A76 is in an identical conformation making identical interactions with 23S RNA (cyan), suggesting that the $\mathrm{E}$ site evolved before the divergence of archaea and bacteria. However, the distinct conformations of $\mathrm{C} 75$ as well as the differences in the proteins (L28 in bacteria; L44e in archaea) suggest that other features of the E site have diverged significantly. 
ate the precursor of the PTC. It has been noticed that independent modules that are duplicated and held by tertiary contacts involving precisely the same type of minorgroove interactions as found in decoding could be the basis for the evolution of RNA in the contemporary $50 \mathrm{~S}$ subunit (Bokov and Steinberg 2009). The evolution of the $30 \mathrm{~S}$ subunit and coded synthesis involving tRNA and mRNA is even less well understood despite decades of speculation. What is clear is that although the contemporary ribosome appears to be a highly complex assembly of RNA and protein, and additionally involves many different protein factors, the high-resolution structures of the ribosome provide strong support for the idea that the essential functions of the ribosome are mediated by RNA and that the ribosome evolved from a primordial RNA world. In so doing, it appears to have been a Trojan horse that accelerated the transformation of that world into the protein world that we know today.

\section{ACKNOWLEDGMENTS}

Work in the author's laboratory is supported by the Medical Research Council (U.K.), the Wellcome Trust, the Agouron Institute, and the Louis-Jeantet Foundation. I thank T. Martin Schmeing for making Figures 1-4 in connection with other publications.

\section{REFERENCES}

Ban N, Nissen P, Hansen J, Moore PB, Steitz TA. 2000. The complete atomic structure of the large ribosomal subunit at $2.4 \AA$ resolution. Science 289: 905-920.

Bashan A, Agmon I, Zarivach R, Schluenzen F, Harms J, Berisio R, Bartels H, Franceschi F, Auerbach T, Hansen HA, et al. 2003. Structural basis of the ribosomal machinery for peptide bond formation, translocation, and nascent chain progression. $\mathrm{Mol}$ Cell 11: 91-102.

Bokov K, Steinberg SV. 2009. A hierarchical model for evolution of 23S ribosomal RNA. Nature 457: 977-980.

Bretscher MS. 1968. Translocation in protein synthesis: A hybrid structure model. Nature 218: 675-677.

Crick FHC. 1966. Codon-anticodon pairing: The wobble hypothesis. J Mol Biol 19: 548-555.

Crick FHC. 1968. The origin of the genetic code. J Mol Biol 38: 367-379.

Ermolenko DN, Spiegel PC, Majumdar ZK, Hickerson RP, Clegg RM, Noller HF. 2007. The antibiotic viomycin traps the ribosome in an intermediate state of translocation. Nat Struct Mol Biol 14: 493-497.

Feinberg JS, Joseph S. 2001. Identification of molecular interactions between P-site tRNA and the ribosome essential for translocation. Proc Natl Acad Sci 98: 11120-11125.

Frank J, Agrawal RK. 2000. A ratchet-like inter-subunit reorganization of the ribosome during translocation. Nature 406: 318 322.

Freistroffer DV, Kwiatkowski M, Buckingham RH, Ehrenberg M. 2000. The accuracy of codon recognition by polypeptide release factors. Proc Natl Acad Sci 97: 2046-2051.

Gao Y-G, Selmer M, Dunham CM, Weixlbaumer A, Kelley AC, Ramakrishnan V. 2009. The structure of the ribosome with elongation factor $\mathrm{G}$ trapped in the post-translocational state. Science 326: 694-699.

Gavrilova LP, Spirin AS. 1974. "Nonenzymatic" translation. Methods Enzymol 30: 452-462.

Gavrilova LP, Kostiashkina OE, Koteliansky VE, Rutkevitch NM, Spirin AS. 1976. Factor-free ("non-enzymic") and factor- dependent systems of translation of polyuridylic acid by Escherichia coli ribosomes. J Mol Biol 101: 537-552.

Guerrier-Takada C, Gardiner K, Marsh T, Pace N, Altman S. 1983. The RNA moiety of ribonuclease P is the catalytic subunit of the enzyme. Cell 35: 849-857.

Kapp LD, Lorsch JR. 2004. The molecular mechanics of eukaryotic translation. Annu Rev Biochem 73: 657-704.

Khaitovich P, Mankin AS, Green R, Lancaster L, Noller HF. 1999. Characterization of functionally active subribosomal particles from Thermus aquaticus. Proc Natl Acad Sci 96: 85-90.

Kool ET. 2000. Synthetically modified DNAs as substrates for polymerases. Curr Opin Chem Biol 4: 602-608.

Korostelev A, Trakhanov S, Laurberg M, Noller HF. 2006. Crystal structure of a 70S ribosome-tRNA complex reveals functional interactions and rearrangements. Cell 126: 1065-1077.

Korostelev A, Asahara H, Lancaster L, Laurberg M, Hirschi A, Zhu J, Trakhanov S, Scott WG, Noller HF. 2008. Crystal structure of a translation termination complex formed with release factor RF2. Proc Natl Acad Sci 105: 19684-19689.

Laurberg M, Asahara H, Korostelev A, Zhu J, Trakhanov S, Noller HF. 2008. Structural basis for translation termination on the 70S ribosome. Nature 454: 852-857.

Lill R, Robertson JM, Wintermeyer W. 1989. Binding of the $3^{\prime}$ terminus of tRNA to 23S rRNA in the ribosomal exit site actively promotes translocation. EMBO J 8: 3933-3938.

Maguire BA, Beniaminov AD, Ramu H, Mankin AS, Zimmermann RA. 2005. A protein component at the heart of an RNA machine: The importance of protein L27 for the function of the bacterial ribosome. Mol Cell 20: 427-435.

Moazed D, Noller HF. 1989. Intermediate states in the movement of transfer RNA in the ribosome. Nature 342: 142-148.

Moore PB. 1988. The ribosome returns. Nature 331: 223-227.

Moore PB. 1993. Ribosomes and the RNA world. In The RNA world (ed. RF Gesteland and JF Atkins), pp. 119-136. Cold Spring Harbor Laboratory Press, Cold Spring Harbor, NY.

Moore VG, Atchison RE, Thomas G, Moran M, Noller HF. 1975. Identification of a ribosomal protein essential for peptidyl transferase activity. Proc Natl Acad Sci 72: 844-848.

Nissen P, Hansen J, Ban N, Moore PB, Steitz TA. 2000. The structural basis of ribosome activity in peptide bond synthesis. Science 289: 920-930.

Nitta I, Ueda T, Watanabe K. 1998. Possible involvement of Escherichia coli $23 \mathrm{~S}$ ribosomal RNA in peptide bond formation. RNA 4: 257-267.

Nitta I, Kamada Y, Noda H, Ueda T, Watanabe K. 1999. Peptide bond formation: Retraction. Science 283: 2019-2020.

Noller HF. 2005. Evolution of ribosomes and translation from an RNA world. In The RNA world, 3rd ed. (ed. RF Gesteland et al.), pp. 287-307. Cold Spring Harbor Laboratory Press, Cold Spring Harbor, NY.

Noller HF, Chaires JB. 1972. Functional modification of 16S ribosomal RNA by kethoxal. Proc Natl Acad Sci 69: 3115-3118.

Noller HF, Hoffarth V, Zimniak L. 1992. Unusual resistance of peptidyl transferase to protein extraction procedures. Science 256: 1416-1419.

Ogle JM, Ramakrishnan V. 2005. Structural insights into translational fidelity. Annu Rev Biochem 74: 129-177.

Ogle JM, Brodersen DE, Clemons WM Jr, Tarry MJ, Carter AP, Ramakrishnan V. 2001. Recognition of cognate transfer RNA by the 30S ribosomal subunit. Science 292: 897-902.

Ogle JM, Murphy FV, Tarry MJ, Ramakrishnan V. 2002. Selection of tRNA by the ribosome requires a transition from an open to a closed form. Cell 111: 721-732.

Rodnina MV, Wintermeyer W. 2001. Fidelity of aminoacyl-tRNA selection on the ribosome: Kinetic and structural mechanisms. Annu Rev Biochem 70: 415-435.

Rodnina MV, Beringer M, Wintermeyer W. 2006. Mechanism of peptide bond formation on the ribosome. $Q$ Rev Biophys 39: 203-225.

Schmeing TM, Ramakrishnan V. 2009. What recent ribosome structures have revealed about the mechanism of translation. Nature 461: 1234-1242.

Schmeing TM, Moore PB, Steitz TA. 2003. Structures of deacy- 
lated tRNA mimics bound to the $\mathrm{E}$ site of the large ribosomal subunit. RNA 9: 1345-1352.

Schmeing TM, Huang KS, Kitchen DE, Strobel SA, Steitz TA 2005a. Structural insights into the roles of water and the $2^{\prime}$ hydroxyl of the P site tRNA in the peptidyl transferase reaction. Mol Cell 20: 437-448.

Schmeing TM, Huang KS, Strobel SA, Steitz TA. 2005b. An induced-fit mechanism to promote peptide bond formation and exclude hydrolysis of peptidyl-tRNA. Nature 438: 520-524.

Schmeing TM, Voorhees RM, Kelley AC, Gao Y-G, Murphy FV IV, Weir JR, Ramakrishnan V. 2009. The crystal structure of the ribosome bound to EF-Tu and aminoacyl-tRNA. Science 326: 688-694.

Schuette JC, Murphy FV IV, Kelley AC, Weir JR, Giesebrecht J, Connell SR, Loerke J, Mielke T, Zhang W, Penczek PA, et al 2009. GTPase activation of elongation factor EF-Tu by the ribosome during decoding. EMBO J 28: 755-765.

Schuwirth BS, Borovinskaya MA, Hau CW, Zhang W, VilaSanjurjo A, Holton JM, Cate JH. 2005. Structures of the bacterial ribosome at $3.5 \AA$ resolution. Science 310: $827-834$.

Selmer M, Dunham CM, Murphy FV IV, Weixlbaumer A, Petry S, Kelley AC, Weir JR, Ramakrishnan V. 2006. Structure of the 70S ribosome complexed with mRNA and tRNA. Science 313: 1935-1942.

Sharma MR, Koc EC, Datta PP, Booth TM, Spremulli LL, Agrawal RK. 2003. Structure of the mammalian mitochondrial ribosome reveals an expanded functional role for its component proteins. Cell 115: 97-108.

Sievers A, Beringer M, Rodnina MV, Wolfenden R. 2004. The ribosome as an entropy trap. Proc Natl Acad Sci 101: 7897-7901.

Spirin AS. 1968. How does the ribosome work? A hypothesis based on the two subunit construction of the ribosome. Curr Mod Biol 2: 115-127.

Spirin AS. 1985. Ribosomal translocation: Facts and models. Prog Nucleic Acid Res Mol Biol 32: 75-114.

Valle M, Sengupta J, Swami NK, Grassucci RA, Burkhardt N, Nierhaus KH, Agrawal RK, Frank J. 2002. Cryo-EM reveals an active role for aminoacyl-tRNA in the accommodation process. EMBO J 21: 3557-3567.

Valle M, Zavialov A, Sengupta J, Rawat U, Ehrenberg M, Frank J. 2003. Locking and unlocking of ribosomal motions. Cell 114: 123-134.

Villa E, Sengupta J, Trabuco LG, LeBarron J, Baxter WT, Shaikh TR, Grassucci RA, Nissen P, Ehrenberg M, Schulten K, Frank J. 2009. Ribosome-induced changes in elongation factor $\mathrm{Tu}$ conformation control GTP hydrolysis. Proc Natl Acad Sci 106: $1063-1068$

Voorhees RM, Weixlbaumer A, Loakes D, Kelley AC, Ramakrishnan V. 2009. Insights into substrate stabilization from snapshots of the peptidyl transferase center of the intact $70 \mathrm{~S}$ ribosome. Nat Struct Mol Biol 16: 528-533.

Weinger JS, Parnell KM, Dorner S, Green R, Strobel SA. 2004. Substrate-assisted catalysis of peptide bond formation by the ribosome. Nat Struct Mol Biol 11: 1101-1106.

Weixlbaumer A, Jin H, Neubauer C, Voorhees RM, Petry S, Kelley AC, Ramakrishnan V. 2008. Insights into translational termination from the structure of RF2 bound to the ribosome. Science 322: 953-956.

Wimberly BT, Brodersen DE, Clemons WM Jr, Morgan-Warren RJ, Carter AP, Vonrhein C, Hartsch T, Ramakrishnan V. 2000. Structure of the 30S ribosomal subunit. Nature 407: 327-339.

Wower IK, Wower J, Zimmermann RA. 1998. Ribosomal protein L27 participates in both $50 \mathrm{~S}$ subunit assembly and the peptidyl transferase reaction. J Biol Chem 273: 19847-19852.

Yusupov MM, Yusupova GZ, Baucom A, Lieberman K, Earnest TN, Cate JH, Noller H.F. 2001. Crystal structure of the ribosome at $5.5 \AA$ A resolution. Science 292: 883-896.

Zaug AJ, Grabowski PJ, Cech TR. 1983. Autocatalytic cyclization of an excised intervening sequence RNA is a cleavage-ligation reaction. Nature 301: 578-583.

Zavialov AV, Mora L, Buckingham RH, Ehrenberg M. 2002. Release of peptide promoted by the GGQ motif of class 1 release factors regulates the GTPase activity of RF3. Mol Cell 10: 789-798. 


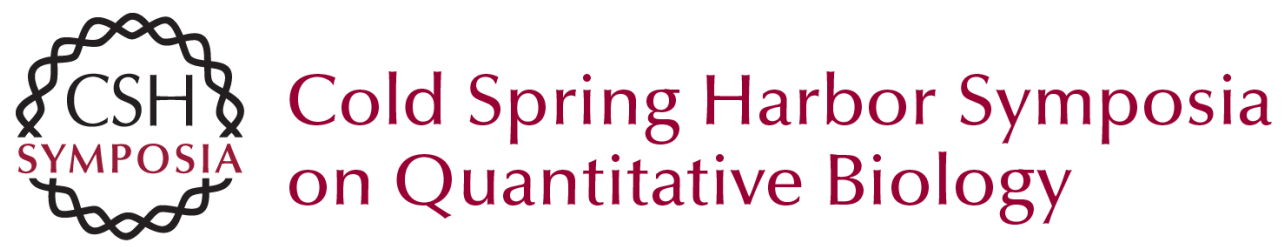

\section{The Ribosome: Some Hard Facts about Its Structure and Hot Air about Its Evolution}

V. Ramakrishnan

Cold Spring Harb Symp Quant Biol 2009 74: 25-33 originally published online December 2, 2009 Access the most recent version at doi:10.1101/sqb.2009.74.032

References This article cites 58 articles, 22 of which can be accessed free at: http://symposium.cshlp.org/content/74/25.full.html\#ref-list-1

\section{License}

Email Alerting Receive free email alerts when new articles cite this article - sign up in the box at the Service top right corner of the article or click here. 